\title{
Transplantacijski turizam
}

\section{Transplant tourism}

\author{
Lada Zibar ${ }^{1,2^{*}}$, Kristina Šunić ${ }^{3}$
}

${ }^{1}$ Klinička bolnica Merkur, Zagreb, Hrvatska

${ }^{2}$ Medicinski fakultet Sveučilišta Josipa Jurja Strossmayera u Osijeku, Osijek, Hrvatska

${ }^{3}$ Dom zdravlja Osijek, Osijek, Hrvatska

\section{*Dopisni autor:}

Prof. dr. sc. Lada Zibar, dr. med.

Klinička bolnica Merkur, Zajčeva 19,

10000 Zagreb

E-mail: ladazibar@gmail.com
Sažetak. Transplantacijski turizam (TT) označava putovanja radi protuzakonitog darovanja i presađivanja (transplantacije, TX, od engl. transplantation) organa, pri čemu darovatelj prodaje "darovani“ organ (trgovina organima). Najčešće se "trguje“ bubrezima. Postoji globalni trend borbe protiv takve prakse. Ipak, kontinuirano se nalaze primjeri TT-a diljem svijeta. Procjenjuje se da je $10 \%$ svih TX-a protuzakonito (često dio TT-a). Nedostatak organa i nesrazmjer socioekonomskog stanja između darivatelja i primatelja organa glavni je uzrok TT-a. Unatoč tomu što „darovatelji“ (prodavatelji) organa tako često rješavaju egzistencijske probleme, prodaja dijelova ljudskog tijela u bilo koju svrhu nije etički prihvatljiva.

Ključne riječi: etika; ilegalna transplantacija; transplantacija organa; trgovina organima; transplantacijski turizam

Abstract. Transplant tourism (TT) considers traveling for the purpose of illegal organ donation or transplantation (TX), where the donor sells the "donated" organ (organ trade). The organ in trade is mostly a kidney. Despite a global combating TT, it is still ongoing across the world. Ten percent of all TXs is estimated to be illegal (often TT). Organ shortage and disproportion in socioeconomic state between the donor and the recipient are the main causes of TT. Despite that by that trade organ donors (sellers) often solve existential problems, selling a part of human body for any purpose is not ethically acceptable.

Key words: ethics; illegal transplantation; organ trade; organ transplantation; transplant tourism

http://hrcak.srce.hr/medicina 


\section{UVOD}

Transplantacijski turizam (TT) vrsta je medicinskog turizma koji najčešće asocira na nezakonite postupke. TT većinom uključuje trgovinu organima $(\mathrm{TO})^{1}$. Postoji trend međunarodne službene osude TO-a i njeno prepoznavanja kao kriminala. Republika Hrvatska (RH) jedna je od zemalja u kojoj je zabranjen TO. Nedostatak organa za presadbu (TX, od engl. transplantation, transplantacija) najčešći je uzrok TO-a. U slučaju prodaje organa darovatelj organa je žrtva situacije zbog koje se odlučuje na prodaju, a primatelj organa je žrtva situacije nedostatka organa u legalnom sustavu. TO stoga pogađa ranjive skupine stanovništva i već stoga ga je potrebno sustavno sprječavati. Neke zemlje, poput Irana, dopuštaju TO. U Iranu se prodaja bubrega vrši pod državnim nadzorom, a sam postupak se odvija posredstvom dviju neprofitnih organizacija - Udruge za podršku bubrežnim pacijentima i Dobrotvorne organizacije za posebne i teške bolesti. Ove organizacije postavljaju pravila i nadziru njihovu primjenu, sve pod okriljem Ministarstva zdravstva². Na Dalekom istoku (u Kini) najvjerojatnije se organi prisilno uzimaju od darovatelja (zatvorenika) i prodaju u korist treće osobe ${ }^{3}$. Siromaštvo, nezaposlenost i neobrazovanost obilježja su država i društava iz kojih se regrutiraju darovatelji organa koji su predmeti TO-a. Bolji životni standard i bolje financijske mogućnosti te očaj zbog bolesti obilježja su potencijalnih kupaca, odnosno primatelja takvih organa. Dodatno je nepovoljno obilježje TO-a, to što se takav TX često izvodi u slabo uređenim državama, u kojima je medicinska skrb ispod odgovarajućeg standarda, što se odnosi i na skrb u vezi s takvim TX-om. Na taj način TX u okviru TO-a i TT-a predstavlja povećan medicinski rizik, i za darovatelja i za primatelja organa, te nerijetko ima neželjen ishod. Prodavanje organa ne smije nikome biti put za materijalnu korist. Neetično je, odnosno nije prihvatljivo prodavati dio svoga tijela ni radi zdravlja druge osobe ${ }^{4}$. Pojam TT-a načelno ne bi morao uvijek biti TO, ako darovatelj i primatelj dolaze u njima stranu državu radi stručne izvedbe TX-a, koja im ili uopće nije na raspolaganju u njihovoj državi ili očekuju stručniju izvedbu u državi u kojoj je žele izvesti, a sve dok se istodobno radi o isključivo altruistič- nom darovanju organa. Sve je više potencijalnih primatelja organa velikog imunosnog rizika (tzv. senzibilizirani ili imunizirani prethodnim TX-om, transfuzijama krvi, trudnoćama) za koje je TX moguć samo u određenim središtima za TX samo određenih država (kakva je npr. i Hrvatska). Tada takav TT treba biti reguliran zakonom države u kojoj se izvodi. Mediji i društvene mreže nerijetko prikazuju pogrešnu sliku o nezakonitom presađivanju radi senzacionalizma, što utječe na stavove pacijenata i javnosti koje se tada temelje na ne-

U slučaju prodaje organa darivatelj organa je žrtva situacije zbog koje se odlučuje na prodaju, a primatelj organa je žrtva situacije nedostatka organa u legalnom sustavu. Trgovina organima stoga pogađa ranjive skupine stanovništva i već zato ju je potrebno sustavno sprječavati.

točnim premisama te se stvara nepovjerenje građana u sustav TX-a. S jedne strane je nužno osuditi TO i boriti se protiv TO-a, a s druge osigurati provođenje legalnog TX-a, dapače, promovirati altruistično darovanje organa. $U$ tom smislu je vrlo važno objektivno izvješćivanje medija. Najčešći organ kojim se „trguje“ u TO, odnosno TT-u, je bubreg.

Ilegalni TX organa uključuje TO, trgovinu ljudima s ciljem odstranjena organa te $\mathrm{TT}^{5}$. U tekstovima na engleskom jeziku osim pojmova trgovina organa (engl. organ trade (TO)) i transplantacijski turizam (engl. transplant tourism (TT)) učestali su i pojmovi promet organima (engl. organ trafficking) i promet ljudima (engl. human trafficking) koji su u kontekstu ove teme uvijek dio ili TO-a ili TT-a, ili dio obje pojave. Ovi će engleski pojmovi gdjegod biti uporabljeni u daljnjem tekstu radi vjerodostojnosti određenih citata. TT podrazumijeva bilo koje putovanje u državu u kojoj putnik nije rezident radi darovanja ili TX-a organa ${ }^{5}$. U revidiranoj Istanbulskoj deklaraciji iz 2018. godine nalaze se slične definicije ${ }^{6}$. Organ trafficking (promet organima) odnosi se na uzimanje organa živog ili preminulog donora bez pristanka ili u zamjenu za materijalnu korist donora ili druge osobe, promet i prodaju organa te pokušaj činjenja prethodno navedenih djela. Trafficking in per- 
sons for the purpose of organ removal opisuje se kao promet ljudima u svrhu odstranjena organa. Potrebno je razlikovati pojmove putovanja radi TX-a (engl. travel for transplantation) te TT. Putovanje radi TX-a postaje TT ako će TX uključivati TO ili trgovinu ljudima u svrhu odstranjena organa. U izvješću projekta HOTT (projekt koji se financira iz fondova Europske unije, EU, od 2012. do 2015., koji se bavio borbom protiv TO-a) rabi se dulji pojam, trafficking in human beings for the purpose of organ removal (engl., promet ljudskim bićima u svrhu odstranjenja organa) ${ }^{7}$. Protokol iz Palerma koji je donesen 2000. pak definira trafficking in persons (engl., promet osobama) kao regrutiranje, prijevoz, premještanje, udomljavanja ili primitak osoba pod prijetnjom ili nasilno ili drugim oblicima prisile, zlouporabe, otimanja, zastrašivanja ili prijevare, zlouporabe moći ili položaj ranjivosti ili davanje ili primanje novčane naknade ili postizanje druge dobiti radi postizanja pristanka osobe da bude pod nadzorom druge osobe radi izrabljivanja. U nabrajanju vrsta izrabljivanja (prostitucija, prisilni rad, ropstvo...) stoji i uzimanje organa. Pri tomu je pristanak na prethodno sa strane žrtve u bilo kojoj od navedenih situacija irelevantan. Protokol iz Palerma odnosi se na organe (bubrezi, jetra, srce, pluća, gušterača) ${ }^{8}$.

\section{POJAVNOST TRANSPLANTACIJSKOG} TURIZMA

Svjetska zdravstvena organizacija procjenjuje da se svake godine izvrši oko 10000 protuzakonitih TX-a organa u svijetu, odnosno da je protuzakonito oko $10 \%$ svih TX-a organa ${ }^{2}$. Godišnja zarada ovih kriminalnih radnji doseže oko milijardu američkih dolara ${ }^{1}$. TO se najviše odvija u nekim azijskim zemljama, poput Indije, Indonezije, Izraela, Kine i Pakistana, latinoameričkim zemljama, Ekvadoru, Kolumbiji, Egiptu, ali donedavno i na nama bliskom području - Kosovu. Kupci organa uglavnom su Izraelci i građani Sjedinjenih Američkih Država (SAD) ${ }^{4}$.

\section{UZROCI TRANSPLANTACIJSKOG TURIZMA}

Čimbenici koji su doveli do povećane „popularnosti" TT-a uključuju nedostatak organa za TX s posljedičnim dugim vremenom čekanja na tzv. listama za TX, siromaštvo i nesrazmjer socioeko- nomskog stanja između različitih država i zemljopisnih područja, pravne prepreke, neznanje i neobrazovanost, religijske prepreke, lakoću i dostupnost međunarodnih putovanja te velike zdravstvene troškove. Primjerice, presađivanje jetre u medicinskoj ustanovi SAD-a stoji otprilike 1700000 kn, dok se u Tajvanu ista usluga dobiva za cijenu nerijetko manju od $50000 \mathrm{kn}^{4}$.

U brojnim državama TX organa uopće se ne izvodi, a u mnogima je, pa i u našoj blizini, vrijeme čekanja dugo i pacijenti nerijetko umiru tijekom čekanja na TX. Broj darovatelja organa rastao je u posljednjih 15 godina stopom od svega $2 \%$ godišnje, dok broj pacijenata na listama čekanja raste za oko 15 - $20 \%$ godišnje ${ }^{1}$. Najbrže raste lista čekanja za bubrežni TX i 15 - 30 \% pacijenata umre čekajući TX. U Eurotransplantu (ET) prosječno se na bubrežni TX čeka $3-5$ godina, dok je medijan čekanja u SAD-u 4 godine ${ }^{5}$. Sustav TX-a od umrlih darovatelja na mnogim mjestima nije dostatno razvijen.

U nekim je državama, poput Irana, prodaja bubrega za TX legalna i praćena financijskom dobiti, koja često predstavlja rješavanje egzistencijskih problema siromašnog darovatelja ${ }^{2}$. Lanac TT-a radi TO-a i TX-a uglavnom koristi darovatelje iz siromašnih krajeva, često mlade muškarce, iz, primjerice, siromašnih dijelova Turske ili Brazila. Mjesta gdje se vrši takav TX najčešće su siromašne države, slabije uređenih javnih sustava, poput, primjerice, Kosova ili Južnoafričke Republike. Uobičajeno je da je darovatelj organa značajno siromašniji od primatelja. Poslijeoperacijska skrb za darovatelja uglavnom bude iznimno loša, ili je uopće nema. Unatoč tomu što je primatelj značajno bogatiji, ni skrb za njega prije- i poslijetransplantacijski nije na primjerenoj razini, većinom u skladu sa standardom države u kojoj se odvija (npr. primatelj ne dobije potrebnu dijalizu peritransplantacijski ili je izvodi nestručno osoblje). Ishodi TX-a iz TO-a, odnosno TT-a, lošiji su u odnosu na legalni TX' ${ }^{9}$.

U nekim sustavima je, da bi darovanje bilo moguće, potrebno da osoba tijekom života iskazuje želju za darovanjem organa (tzv. opt-in sustav). To ograničava broj umrlih darovatelja. $\mathrm{S}$ druge strane, neki sustavi omogućavaju uzimanje organa ako se osoba tijekom života tome nije protivila (tzv. opt-out sustav). U nekim se zemljama razgo- 
vara s članovima obitelji i traži se zakonski obvezna dozvola obitelji za presađivanje. Ipak, i u zemljama gdje ne postoji zakonska obveza traženja dozvole obitelji za presadbu organa, običaj je da se članove bliže obitelji pita za dozvolu. I ovo predstavlja ograničenje broju umrlih darovatelja $\operatorname{organa}^{10}$. Osim što je, npr. u Iranu, TO dozvoljen, a u razvijenim državama većinom zakonom zabranjen, određeni segmenti u prije-, peri- i poslijetransplantacijskim postupcima zbog pravne neodređenosti „prolaze“ jednostavno, što TO čini lakšim². Primjer je država u kojoj je TO ilegalan, no u poslijetransplantacijskom praćenju se primatelj organa iz TX-a izvršenoga u drugoj državi, vrlo vjerojatno putem TO-a, javlja specijalistu prvo spomenute države u kojoj je rezident. Taj liječnik zbog čuvanja liječničke tajne ne prijavljuje sumnju u TO i na taj način, nečinjenjem, podržava TO i TT.

TO koristi darovatelje iz najnižih društvenih slojeva koji nisu samo siromašni, već i neobrazovani. Oni često nisu svjesni stvarnog rizika u koji se upuštaju, nemaju znanja o mogućim komplikacijama, te u darovanju vide samo financijsku dobit. Iz izvješća s Kosova vidljivo je da niti novčana naknada ne dolazi promptno, nego je uvjetovana regrutiranjem sljedećeg darovatelja za $T^{11}$. U tom lancu darovatelji, žrtve, ne samo da ne razumiju pojedinosti situacije u kojoj se nalaze, već najčešće ne razumiju ni jezik ljudi uključenih u organizaciju TO-a.

U svijetu i dalje veliku ulogu u stvaranju društvenih normi imaju religijska uvjerenja. Poneke religije se protive darovanju i TX-u organa. U zemljama u kojima je većina stanovništva islamske vjeroispovijesti znatno je manji broj TX-a od umrlog darovatelja, a veći udio onih u kojima su organi uzeti od živih darovatelja. Razlog je tome dijelom stav sljedbenika islamske vjeroispovijesti kojemu nije dopušteno sakaćenje mrtvoga tijela ${ }^{12}$. Ortodoksni Židovi pak ne prihvaćaju koncept moždane smrti te se organi i tkiva za TX mogu uzeti samo od neživih darovatelja u kojih je smrt potvrđena na temelju kardiopulmonalnih kriterija ${ }^{12}$.

\section{POVIJEST TRANSPLANTACIJSKOG TURIZMA}

Već posljednjih desetljeća 20. stoljeća pacijenti katkad odlaze na Srednji ili Daleki istok „po bubreg“. Osamdesetih i devedesetih godina 20. sto- ljeća i u Hrvatskoj smo viđali takve slučajeve, pa smo i sami svjedočili neželjenim posljedicama koje su znale biti teške i fatalne. Nerijetko su se vraćali u mrtvačkim kovčezima, poput jednog mladog pacijenta iz dijaliznog središta u kojemu sam tada, početkom devedesetih godina prošlog stoljeća, radila. Devedesetih godina svjedočila sam i dolasku hrvatske pacijentice iz Indije, gdje joj je recentno bio presađen bubreg, s velikom dubokom otvorenom inficiranom poslijetransplantacijskom ranom svih slojeva trbušne stijen-

Prodavanje organa ne smije nikome biti put za materijalnu korist. Neetično je, odnosno nije prihvatljivo prodavati dio svoga tijela ni radi zdravlja druge osobe.

ke iznad presatka, koja je „cijelila“ per secundam, tako da je presađeni bubreg bio dostupan oku. Istodobno je imala bizarne infiltrate u mozgu, izazvane nepoznatim, vjerojatno Europljanima egzotičnim, mikrobiološkim uzročnikom. Nažalost, pacijentica je uskoro preminula unatoč uloženim stručnim naporima*. Prepričavanja o uvjetima u kojima su se vršili kirurški zahvati ukazivala su na izrazito lošu osnovnu higijenu i manjkavu medicinsku skrb. Cijene takvih bubrega kretale su se oko 10000 do 20000 američkih dolara. Sam darovatelj bi dobivao tek mali dio te svote. Odlazak u Indiju, Pakistan ili srednjoistočne zemlje bivšeg Sovjetskog Saveza radi TX-a nastavlja se i danas ${ }^{11}$. Ovakva povijest, dakle, nije prekinuta na svjetskoj razini, no, nasreću, jest za hrvatske državljane, u skladu s aktualno većom dostupnosti TX-a u našoj zemlji.

Nadalje navodimo podatke o nekoliko konkretnih lokaliteta u svijetu u kojima se susreće TT i TO radi TX-a.

Indijska bolnica Gurgaon dugo je bila jedno od glavnih odredišta za protuzakonit bubrežni TX. Siromašni indijski radnici prodavali bi bubrege za oko 300 dolara nakon što bi ih posrednici prevarili ili prisilili na to. Čovjek iza cijele priče, kojega je 2008. uhitio indijski Središnji ured za istrage, bio je izvjesni Amit Kumar. On je dvadesetak godina provodio operacije bez ikakve medicinske kvalifikacije, osnovavši tako jedan od najvećih lanaca za

*Iskustvo prve autorice 
TO na svijetu. Organi su dolazili iz siromašnih sela diljem Indije, a prodavali su ih dalje u Grčku, Tursku, Kanadu, SAD i na Bliski istok ${ }^{3}$. U pokrajini Punjab u Pakistanu zabilježeni su brojni slučajevi TO-a, a procjenjuje se da oko 1000 ljudi godišnje u Pakistanu proda svoj organ. Primatelji uglavnom dolaze iz Velike Britanije i Saudijske Arabije, te za organ plaćaju od 30000 do 90000 američkih dolara. Prema izvješćima pakistanske policije, darovatelji organa dobiju manje od desetine navedenog iznosa ${ }^{13}$.

U okviru projekta HOTT prije nekoliko godina otkriven je tzv. slučaj Medicus na Kosovu. U nama ne tako dalekoj državi godinama se održavao protuzakonit sustav koji je uključivao TT radi TO-a i TX-a. Krivci su osuđeni na zatvorske kazne. Nažalost, broj parova darovatelj - primatelj, žrtava ove prakse, nije mogao biti točno utvrđen. Postojali su dokazi da je ovoj organizaciji pogodovala i državna administracija. Ovo je bio primjer TT-a gdje su „turisti“ bili i darovatelj i primatelj bubrega, pa čak i kirurg - operater. Slučaj se počeo razotkrivati nakon što je darovatelj kolabirao na aerodromu, „otpušten“ vrlo brzo nakon uzimanja organa, bez primjerene poslijeoperacijske skrbi ${ }^{11}$. U okviru projekta HOTT utvrđen je i slučaj Netcare u Južnoafričkoj Republici. Darovatelji su bili siromašni mladići iz Brazila, a primatelji najčešće bogatiji Izraelci ${ }^{11}$.

Poznato je da se organi za TO uzimaju zatvorenicima u Kini i prodaju primateljima, strancima, te se godinama vrši međunarodni pritisak na Kinu da se prekine $s$ takvom praksom. U literaturi se umreženost pravosuđa u TO u ovakvu praksu naziva perverznom, i upravo ga taj atribut najbolje opisuje. Slučajevi TO-a, konkretno trgovine bubrezima koji su uzeti od zatvorenika, zabilježeni su i na Filipinima, gdje su primatelji najčešće dolazili iz Japana. Ondje čuvari biraju zatvorenike koji im izgledaju najzdravije te tako zatvorenici prisilno postaju žrtvama TO-a ${ }^{14}$.

\section{PRIKRIVENO TRGOVANJE ORGANA}

Nedavno je u našoj državi artikuliran problem tzv. prikrivenog TO-a (engl. hidden organ trade), uglavnom u okviru TT-a. Radi se o parovima po-

\footnotetext{
${ }^{* *}$ Pojam prve autorice
}

tencijalnih darovatelja i primatelja organa (tzv. usmjereno darovanje potencijalnog darovatelja određenom primatelju), dakle, srodnih ili nesrodnih, koji se deklariraju kao bliski i isključivo altruističnog motiva za darovanje organa. Dosadašnje odredbe koje predviđaju procjenu etičnosti darovanja (de lege lata, lat., prema važećem zakonu) su takve da nakon postupka nerijetko ostavljaju sumnju na TO, unatoč izjavama darovatelja i primatelja koji isto negiraju. Očekuje se primjerenija legislativa u bliskoj budućnosti (de lege ferenda, lat., prema zakonu koji treba donijeti).

\section{ODNOS PREMA TRANSPLANTACIJSKOM TURIZMU}

Brojni su akti doneseni posljednjih desetljeća koji na međunarodnoj razini osuđuju TO (2000. g. United Nations Protocol against Trafficking in Persons - tzv. Palermo Protocol, Protokol protiv prometa ljudima Ujedinjenih naroda, tzv. Protokol iz Palerma, 2011. EU Directive on preventing and combating trafficking in human beings and protecting its victims, Uredba Europske unije o sprječavanju i borbi protiv prometa ljudskim bićima i zaštite žrtava, 2014. Council of Europe Convention against Trafficking in Human Beings, Konvencija Vijeća Europe protiv prometa ljudima, Council of Europe Convention against Trafficking in Human Organs, Konvencija Vijeća Europe protiv prometa ljudskim organima) ${ }^{8,15,16}$. Među važnijima i u transplantacijskim krugovima poznatijima je i tzv. Istambulska deklaracija (Deklaracija o trgovini organima i transplantacijskom turizmu), donesena 2008. godine, na inicijativu Međunarodnog transplantacijskog društva (The Transplantation Society, TTS) i Međunarodnog nefrološkog društva (International Society of Nephrology, ISN), na skupu sudionika iz 78 zemalja svijeta. Nastala je na temeljima Rezolucije br. WHA 57.18 Svjetske zdravstvene skupštine iz 2004. godine koja je potaknula države članice na zaštitu najsiromašnijih i najnezaštićenijih od TT-a i TO- ${ }^{17}$. Pod pokroviteljstvom pape Franje 2017. je u Vatikanu održan skup protiv TO-a i TT-a (Pontifical Academy of Sciences Summit on Organ Trafficking), čiji je službeni zaključak ustvrdio da svi religijski, politički i društveni vođe, kao i nacionalna i međunarodna zakonodavstva, trebaju prepoznati 
organ trafficking kao pravi KRIMINAL protiv ljudskosti i boriti se protiv tog kriminala zajedničkim snagama svih u svijetu. Također se sustavno ukazuje na ODGOVORNOST liječnika koji sudjeluju u ovakvom TX-u ${ }^{18}$. Osim kriminalizacije ovakve prakse, ističe se njena neetičnost, što je važno razlikovati jer je nerijetko „zakon etički neutralan“ (I. Kant, Kritika praktičnog uma). U slučaju pravnih praznina moralno/etičko obilježje trebalo bi biti putokaz za ponašanje društva, a osobito liječnika. Zakon RH 1. ožujka 2019. potvrđuje Konvenciju Vijeća Europe protiv trgovanja ljudskim organima ${ }^{19}$. Unatoč izvrsnoj praksi TX-a organa u $\mathrm{RH}$, iznenadila su nas izvješća istraživanja među pacijentima na nadomještanju bubrežne funkcije u domaćem nefrološkom (dijaliznom) središtu o stavovima i znanju povezanima za protuzakonit TX. U istraživanju iz 2016. čak četvrtina pacijenata na kroničnoj dijalizi mislila je da se u Hrvatskoj vrši ilegalni TX ${ }^{20}$. Ipak, manje je takvih odgovora (7 \%) bilo u istraživanju iz 2017., među pacijentima s funkcionirajućim bubrežnim presatkom ${ }^{21}$.

\section{NAČINI BORBE PROTIV TRANSPLANTACIJSKOG TURIZMA}

U borbi protiv TO-a osnovno je prvo javno i službeno prepoznati i osuditi sve pojavnosti prometa ljudima i ljudskim organima radi TX-a u kontekstu TO-a, uključujući i uzimanje organa zatvorenicima, kao i plaćanje za organe bližnjima umrlih darovatelja organa. S druge je strane važno promovirati altruistično darovanje organa. Borba protiv TT-a treba uključiti sustav državne vlasti, religijske vođe, ustanove i tijela koja brinu o etičnosti liječnika, zakonodavce i pravosuđe, međunarodne organizacije, školstvo i znanost. Osim zakonskih, svjetonazorskih, obrazovnih i etičkih oruđa koja predstavljaju podršku ideji o negativnosti TO-a, ekonomski napredak je taj koji utječe na sve prethodno navedeno i umanjuje uzroke TO-a. No, korelacija između ekonomskog napretka i realizacije ideološki određene negativnosti TO-a nije jednoznačna. U bogatim i razvijenim državama etabliranje tzv. liberalnih mogućnosti (poput npr. eutanazije) otvara nove načine etički upitnih TX-a (a možda i TO-a). S druge strane, ekonomski napredak samo ponekog dijela svijeta ili pojedinih država povećava nesrazmjer bogat- stva u odnosu na siromašne države i na taj način čine TO prvima dostupnijim, a drugima još jednostavnijem rješenju egzistencijskih problema. Inzistiranje na samodostatnosti u organima za TX i regionalnoj suradnji (pod ovo možemo svesti sustav ET-a kojemu Hrvatska pripada) preporučen je način borbe protiv TO-a, a hrvatski uspjesi u darovanju i TX-u organa, uz nepostojanje TO-a, svjedoče da ekonomsko bogatstvo nije jedino što je presudno. Velik je izazov u borbi protiv TO-a identificiranje tzv. trećih osoba, koji posreduju pri

Zbog potrebe za organima za transplantaciju koje nisu zadovoljene legalnom „ponudom“, zbog nesrazmjera bogatih i siromašnih stanovnika i dijelova svijeta te zbog neznanja i neetičnosti dionika sustava, susrećemo se sa svjetski prisutnom i nezanemarivo prevalentnom pojavom trgovanja organima.

TO-u i koji su dio kriminalnog kruga s isključivo lukrativnim motivom, bez obilježja žrtve (koja imaju i darovatelji i primatelji organa u TO-u), odnosno bez olakotnih okolnosti za svoje nedjelo.

Posebno je područje posrednog utjecaja na nedostatak organa zapravo utjecaj na rast potrebe za organima. Radi se o sustavu sprječavanja i pravodobnog prepoznavanja te primjerenog liječenja bolesti koje dovode do potrebe za nadomještanjem funkcije organa. Ovakav pristup najetičniji je i vjerojatno bi bio dugoročno najučinkovitiji. On opet uključuje vlast (ministarstva, radi donošenja odluka, i zakonodavce, radi zakonskog reguliranja „akcija“), liječnike (od javnog zdravstva preko primarne prakse do specijalista, radi provođenja „akcija“), školstvo (edukacija o zdravom načinu života, zdravstvena pismenost), vjerske predstavnike (edukacija, „svjedočenje“ primjerenog svjetonazora), znanost (napredak u medicinskoj skrbi na svim razinama, od prevencije do liječenja) i osiguravatelja zdravstvenog osiguranja (radi financiranja pojedinih sastavnica „akcija“).

\section{ZAKLJUČAK}

TT je u ovom članku promatran u pejorativnom svjetlu, kao dio TO-a. Zbog potrebe za organima za TX koji nisu zadovoljeni legalnom „ponudom“, zbog nesrazmjera bogatih i siromašnih stanovni- 
ka i dijelova svijeta te zbog neznanja i neetičnosti dionika sustava TO-a susrećemo se sa svjetski prisutnom i nezanemarivo prevalentnom pojavom TO-a. Istodobno se posljednjih desetljeća, iz godine u godinu, ulažu napori različitih međunarodnih organizacija i nacionalnih institucija u borbi protiv TO-a. Hrvatska aktivno podržava takvu borbu i nije područje u kojemu je TO prepoznat problem. Naprotiv, izvrsni uspjesi u darovanju i TX-u organa mogu se smatrati zaslužnima za uzoritost Hrvatske u legalnom i etičnom sustavu darovanja i TX-a organa, unatoč tomu što Hrvatska ne pripada bogatom dijelu svijeta. No, opreza nikada dosta, pa se budnost (vigilancija) trajno održava čak i u našoj „oazi“ reda.

Izjava o sukobu interesa: Autori izjavljuju da ne postoji sukob interesa.

\section{LITERATURA}

1. Global observatory on donation and transplantation (GODT).org [Internet]. Global transplant data. Data reports. [cited 2017 June 13]. Available from: http://www. transplant-observatory.org/.

2. Griffin A. Kidneys on demand. BMJ 2007;334(7592): 502-5.

3. Bhattacharjee Y. The Downfall of India's Kidney Kingpin [Internet]. Discover Magazine. [cited 2019 December 14]. Available from: http://discovermagazine.com/2010/ apr/09-the-downfall-of-india.s-kidney-kingpin.

4. Insider Monkey.com [Internet]. 10 Black Market Organ Trade and Trafficking Facts, Statistics, and Stories. [cited 2017 May 25]. Available from: http://www.insidermonkey.com/blog/10-black-market-organ-trade-and-trafficking-facts-statistics-and-stories-534744/2/.

5. Decodedscience.org [Internet]. Small - Jordan D. Organ harvesting, human trafficking, and the black market. [cited 2017 June 2]. Available from: https://www.decodedscience.org/organ-harvesting-human-traffickingblackmarket/56966.

6. Declarationofistanbul.org [Internet]. The Declaration of Istanbul on Organ Trafficking and Transplant Tourism (2018 Edition). [cited 2019 August 21]. Available from: http://www.declarationofistanbul.org/.

7. HOOT project.com [Internet]. Trafficking in persons for the purpose of organ removal. [cited 2017 May 27]. Available from: http://hottproject.com/about-the-crime/trafficking-in-persons.html.

8. Refworld.org [Internet]. UN General Assembly: Protocol to Prevent, Suppress and Punish Trafficking in Persons, Especially Women and Children, Supplementing the United Nations Convention against Transnational Organized Crime, 15 November 2000. [cited 2019 December 16].
Available from: //www.refworld.org/docid/4720706c0. html.

9. Uptodate.com [Internet]. Vella J, Brennan C, Lam A: Organ trafficking, transplant tourism, and transplant commercialism. [cited 2019 December 16]. Available from: https://www.uptodate.com/contents/organ-traffickingtransplant-tourism-and-transplant-commercialism.

10. Kowalski RM, Payne HS. The decision to donate: a model of decision making among individuals and families. Prog transplant 2006;16(1):87-91.

11. Ambagtsheer F, Weimar W, (Eds.). Trafficking in Human Beings for the Purpose of Organ Removal. Lengerich: Pabst Science Publishers; 2016.

12. Miller AC, Ziad-Miller A, Elamin EM. Brain death and Islam: the interface of religion, culture, history, law, and modern medicine. Chest 2014;146:1092-101.

13. Reuters.com [Internet]. Haider Z. Debt drives kidney harvesting in Pakistan's citrus orchards. [cited 2019 December 14]. Available from: https://www.reuters.com/ article/us-pakistan-trafficking-organs/debt-drives-kidney-harvesting-in-pakistans-citrus-orchards-idUSKCN1BM17K.

14. Channelnewsasia.com [Internet]. Promchertchoo P. Kidney for sale: Inside Philippines' illegal organ trade. [cited 2019 December 14]. Available from: https://www.channelnewsasia.com/news/asia/kidney-for-sale-philippinesillegal-organ-trade-12007722.

15. Eur-lex.europa.eu [Internet]. Directive 2011/36/EU of the European Parliament and of the Council of 5 April 2011 on preventing and combating trafficking in human beings and protecting its victims, and replacing Council Framework Decision 2002/629/JHA. [cited 2019 December 16]. Available from: https://eur-lex.europa.eu/legalcontent/en/TXT/?uri=CELEX\%3A32011L0036.

16. Coe.int [Internet]. Council of Europe Treaty Series - No. 216 Council of Europe Convention against Trafficking in Human Organs. [cited 2019 December 16]. Available from: https://rm.coe.int/16806dca3a.

17. Hrvatska donorska mreža.hr [Internet]. Istanbulska deklaracija. [cited 2017 June 18]. Available from: http:// www.hdm.hr/2008/06/25/istanbulska-deklaracija-2/.

18. The Pontificial Academy of Sciences.va [Internet]. Declaration of the Vatican Pontifical Academy of Sciences. [cited 2019 December 15]. Available from: http://www.pas.va/ content/accademia/en/events/2017/organ_trafficking/ statement.html.

19. Sabor.hr [Internet]. Konačni prijedlog zakona o potvrđivanju Konvencije Vijeća Europe protiv trgovanja ljudskim organima, drugo čitanje, P. Z. br. 569 - predlagateljica: Vlada Republike Hrvatske. [cited 2019 December 16]. Available from: https://www.sabor.hr/hr/ konacni-prijedlog-zakona-o-potvrdivanju-konvencije-vijeca-europe-protiv-trgovanja-ljudskim-organima.

20. Zibar $L$ et al. What do Croatian chronic hemodialysis patients think about illegal kidney transplantations? ISCB; Jerusalem, Israel, 2016.

21. Duvnjak K. Stavovi bolesnika s bubrežnim presatkom o ilegalnom bubrežnom presađivanju. Osijek: Medicinski fakultet, 2017. Diplomski rad. 